\title{
KAJIAN PEMANFAATAN LIMBAH PERKEBUNAN UNTUK SUBSTITUSI BAHAN PEWARNA ALAMI BATIK
}

\author{
Review: Use of Plantations Waste for Substitution of Natural Batik Color Materials \\ Edi Eskak dan Irfa'ina Rohana Salma \\ Balai Besar Kerajinan dan Batik \\ Jl. Kusumanegara No. 7 Yogyakarta \\ e-mail: eskakedi@gmail.com
}

\begin{abstract}
Abstrak: In the beginning, batik making used dyes from natural materials taken from the environment around the craftsmen. The discovery of synthetic dyes with several advantages over natural dyes resulted in switching and use it. Synthetic dyes have several advantages, which are; brighter, various types of colors, strong coloring, stable, not easily wear off, easily obtained, easy to use, and easy to store. However, critics from health and environmental experts state that the use of synthetic dyes can cause health problems and environmental pollution. It makes consumers and batik craftsmen to realize to re-use natural dyes. Natural dyes are non-toxic, biodegradable, environmentally friendly, available in the natural surroundings, easily renewed, and they are not imported materials. One source of natural dyes comes from plantation waste. The waste from plantations those can be used for natural dyes batik are cocoa rind, coconut rind, palm oil shells, rambutan rind, mangosteen rind, guava leaves, mango leaves, and avocado leaves. Increased of public awareness of health and environment safe, making natural dyes as recommended dyes, so that batik products with natural dyes have a better market.
\end{abstract}

Keywords: review, waste utilization, plantation products, natural dyes, batik

\begin{abstract}
Abstrak: Produk batik dengan warna alam sedang digemari masyarakat seiring meningkatnya kesadaran masyarakat terhadap kesehatan diri dan lingkungan hidup. Pewarna alami memiliki kelebihan yaitu aman untuk kesehatan, aman dalam proses pengerjaannya, tidak mencemari lingkungan, serta tidak perlu impor. Pewarna sintetis lebih praktis penggunaannya, namun berdampak kurang baik terhadap kesehatan, limbahnya termasuk berbahaya dan mencemari lingkungan, serta merupakan bahan impor. Kendala pewarna alami untuk batik adalah masih terbatasnya pasokan bahan dikarenakan masih mengambil dari kebun atau hutan. Oleh karena itu perlu dicari pewarna alami dari sumber lain yang ketersediaannya melimpah dan kontinuitas pasokannya lancar yakni memanfaatkan limbah perkebunan. Kajian ini bertujuan untuk mengetahui jenis-jenis limbah perkebunan yang dapat dimanfaatkan untuk bahan pewarna alami batik. Limbah dipilih dari sisa buangan dari proses pengupasan buah dan limbah buangan dari pemeliharaan tanaman, sehingga murah dan tidak merusak tanaman produktif.
\end{abstract}

Kata kunci: kajian, pemanfaatan limbah, hasil perkebunan, pewarna alami, batik

\section{PENDAHULUAN}

Dewasa ini penggunaan zat pewarna alami untuk batik digemari kembali. Pada mulanya pewarnaan batik tradisional menggunakan zat pewarna alami yang diambil dari lingkungan sekitar pengrajin (Gardjito, 2015). Batik merupakan kain bermotif hias yang proses pembuatannya melalui pewarnaan kain dengan menggunakan teknik celup 
rintang. Bahan perintangnya adalah lilin panas (hot wax) yang dituliskan/digambarkan menggunakan alat canting (Salma \& Eskak, 2019). Motif hias pada kain terbentuk karena pada waktu dicelupkan dalam cairan zat warna, terdapat bagian yang sengaja dirintangi dengan lilin. Bagian kain yang dirintangi itulah yang menimbulkan gambar motif hias batik. Pemberian warnanya menggunakan zat yang mampu meresap kuat ke dalam serat-serat kain dan dapat bertahan lama tanpa mengalami kelunturan. Bahan pewarna untuk batik ada dua jenis yaitu zat pewarna alami dan zat pewarna sintetis. Zat pewarna alami diambil dari ekstrak bahan alam, sedangkan zat pewarna sintetis merupakan pewarna tiruan yang dihasilkan oleh pabrik (Susanto, 2018). Indonesia merupakan negara yang kaya akan sumber daya alam, termasuk bahan pewarna alami. Anugrah dari Tuhan ini mestinya disyukuri dengan mengeksplorasi sumber daya alam secara arif dan bijaksana untuk kemanfaatan yang besar bagi kesejahteraan masyarakat (Yoga \& Eskak, 2015). Sumber zat pewarna alami untuk batik utamanya adalah dari tumbuhan dan sudah digunakan sejak abad ke-17 (Suheryanto, 2017), namun dapat pula bersumber dari binatang, mikroorganisme dan mineral (Visalakshi \& Jawaharlal, 2013). Dalam tulisan ini akan fokus pada bahan pewarna alami dari sumber tumbuhan.

Semua bagian tumbuhan yaitu akar, batang kayu, kulit, daun, bunga, dan buah, apabila diekstrak dapat menghasilkan zat pewarna. Beberapa sumber tanaman yang sudah dimanfaatkan untuk pewarnaan alami batik adalah daun nila (Indigofera $s p$.) yang menghasilkan warna biru tua, kulit kayu tingi (Ceriops candolleana arn): coklat kemerahan, kayu tegeran (Cudraina javanensis): coklat dan hitam, kunyit (Curcuma sp.): kuning, teh (Camelia sp.): coklat, akar mengkudu (Morinda citrifolia): coklat kemerahan dan coklat kehitaman, kulit kayu jambal (Pelthophorum ferruginum): coklat kemerahan, kesumba (Bixa orellana): kuning dan merah, dan daun jambu biji (Psidium guajava): coklat kehijauan dan coklat kehitaman (Susanto, 2018). Dalam perkembangannya telah ditemukan pemanfaatan beberapa jenis tumbuhan lainnya antara lain: ekstrak daun jati (Tectona grandis) menghasilkan warna kemerahan dan coklat (Satria \& Suheryanto, 2016). Ekstrak kulit buah jolawe (Terminalia bellerica): abu-abu dan coklat (Andansari \& Nadir, 2017). Ekstrak kayu secang (Caesalpinia sappan L): merah (Lestari et al., 2018). Ekstrak kelopak bunga rosella (Hibiscus sabdariffa $L$ ): merah, jingga, dan ungu (Sima, 2019). Sedangkan sumber pewarna alami dari potensi tumbuhan laut, misalnya ekstraksi rumput laut Gracilaria sp. menghasilkan warna coklat (Haerudin et al., 2017). Ekstraksi zat warna dari rumput laut Sargassum sp. menghasilkan warna coklat (Ruslan \& Wiraningtyas, 2019).

Warna yang dikehendaki dalam batik untuk sandang adalah warna yang cemerlang dan tidak luntur, maka pada proses pewarnaan alami perlu ditambahkan bahan mordan dan atau fiksator untuk pengikat zat warna. Bahan fiksasi perlu dipilih dari bahan yang ramah lingkungan supaya limbahnya tidak menjadi masalah pada lingkungan. Fiksator yang sering digunakan antara lain: air kapur, boraks, cuka, daun jambu batu, gula aren, gula batu, gula jawa, jeruk nipis, jeruk sitrun, pisang klutuk, prusi, sendawa, tape, tawas, tetes, dan tunjung. Perbedaan jenis fiksator berpengaruh terhadap arah warna yang dihasilkan (Handayani \& Maulana, 2013; Pujilestari, 2014; Atika et al., 2016). Penggunaan mordan dari logam berat sebaiknya dibatasi, karena penggunaan yang berlebihan dapat mencemari lingkungan. Visalakshi dan Jawaharlal (2013) menyarankan batas penggunaan mordan yaitu untuk As (1 ppm), Pb (1 ppm), Cd (2 ppm), Cr (2 ppm), Co (4 ppm), Cu (50 ppm), Ni (4 ppm), dan Zn (20 ppm), sedangkan penggunaan mordan yang berasal dari logam $\mathrm{Al}, \mathrm{Fe}$ dan Sn tidak dibatasi. 
Penggunaan zat pewarna alami untuk batik adalah tindakan nyata aksi cinta lingkungan hidup. Bahan ramah lingkungan adalah bahan yang tidak beracun saat proses pengerjaannya (aman bagi pekerja), tidak meninggalkan residu racun pada produk yang dihasilkannya (aman bagi konsumen), serta limbahnya mudah didegradasi oleh alam (aman bagi lingkungan). Limbah daun misalnya ketika tidak dimanfaatkan untuk bahan pewarna alami batik, dapat dimanfaatkan untuk makanan ternak dan pupuk kompos. Bahkan ketika sama sekali tidak dimanfaatkan pun, tidak berdampak buruk bagi lingkungan, karena sudah merupakan daur ekologis alamiah. Tetapi dengan memanfaatkannya berarti telah meningkatkan nilai dari bahan alami tersebut. Pemanfaatan limbah alami merupakan ikhtiar kreatif dalam memanfaatkan sumber alam secara optimal. Ada peningkatan nilai ekonomi dari bahan sisa yang biasanya hanya dibuang tersebut (Eskak, 2014).

\section{Dampak Negatif Zat Pewarna Sintetis}

Zat pewarna sintetis ditemukan oleh WH Perkin tahun $1856 \mathrm{M}$, yang memiliki banyak keunggulan dibandingkan dengan zat pewarna alami, antara lain memberikan berbagai macam warna dengan rentang luas dan bernuansa terang serta tidak mudah luntur (Kant, 2012). Harganya murah dan mudah diperoleh di pasar (Suarsa et al., 2011), lebih stabil dan lebih tahan terhadap berbagai kondisi lingkungan serta daya mewarnainya lebih kuat (Kartina et al., 2013). Penyimpanan bahan pewarna sintetis lebih ringkas menghemat ruang serta penyiapan bahan untuk proses pewarnaan lebih mudah. Penggunaan pewarna sintetis meningkatkan produktivitas pengrajin batik, karena lebih praktis dan mudah digunakan serta proses pencelupan warna yang lebih cepat selesai. Diversifikasi motif hias batik yang dihasilkan pun lebih variatif dengan komposisi warna yang lebih kaya.

Pertimbangan efektivitas dan efisiensi serta ekonomisnya penggunaan zat warna sintetis menyebabkan peningkatan penggunaan zat pewarna sintetis (Paryanto et al., 2013). Penerimaan yang baik dari konsumen terhadap produk batik berpewarna sintetis, menyebabkan sebagian besar produsen batik pun beralih menggunakan zat pewarna sintetis. Selain itu beberapa alasan ditinggalkannya penggunaan pewarna alami dalam industri batik antara lain: (1) Proses penyiapan zat pewarna alami memerlukan waktu yang panjang, sehingga mengakibatkan biaya produksi menjadi mahal, (2) Bahan pewarna alami kurang tahan lama disimpan sebelum proses pewarnaan, (3) Warnanya kurang bervariasi, kurang cemerlang, dan relatif mudah luntur dan pudar, (4) Proses pewarnaan memerlukan waktu yang panjang dan pencelupan harus dilakukan berulang-ulang untuk mendapatkan warna yang lebih tua. Kelemahankelemahan tersebut menyebabkan penggunanaan pewarna alami untuk batik semakin ditinggalkan.

Namun, ternyata limbah cair dari pewarna sintetis pada proses batik merupakan limbah yang berkadar pencemaran tinggi (Muniarti et al., 2015) karena beberapa pewarna dapat terdegradasi menjadi senyawa yang bersifat karsinogenik dan beracun. Pembuangan limbah pewarna sintetis ke perairan dapat berdampak pada penipisan oksigen terlarut, kualitas perairan menurun dan menyebabkan kematian makhluk hidup yang tinggal di dalamnya karena kekurangan oksigen atau terkontaminasi senyawa beracun (Widjajanti et al., 2011). Limbah pewarna dapat meningkatkan kekeruhan air, berbau, dan mencegah penetrasi sinar matahari. Limbah yang mengalir ke sawah dapat menyumbat pori-pori tanah yang berakibat pada hilangnya produktivitas tanah, tekstur tanah mengeras, dan menghalangi penetrasi akar tumbuhan (Kant, 2012). Beberapa dampak negatif yang timbul akibat keberadaan pewarna yang melebihi ambang batas yaitu terjadinya iritasi mata, iritasi kulit, gangguan saluran pernafasan bahkan dapat menimbulkan 
kematian (Yuningrat et al., 2018). Gugus azo karena sifat aromatiknya diduga keras menyebabkan penyakit kanker kulit (karsinogenik) dan mencemari lingkungan (Siregar, 2016). Penggunaan zat warna sintetis baik pada industri besar maupun industi menengah kecil secara nyata menghasilkan limbah yang mencemari lingkungan (Rame et al., 2017). Oleh karena itu perlu dilakukan langkahlangkah strategis untuk mengurangi dampak buruk tersebut, salah satunya adalah dengan menggiatkan pemanfaatan kembali zat pewarna alami.

\section{Saatnya Kembali Menggunakan Zat Pewarna Alami}

Seiring waktu berjalan, tingkat pendidikan masyarakat yang semakin meningkat, kesadaran kesehatan dan lingkungan pun semakin tumbuh, membuahkan kepedulian untuk hidup secara lebih sehat di lingkungan yang bersih. Pencemaran akibat penggunaan pewarna sintetis secara masif pun mulai terlihat nyata mengganggu kesehatan manusia dan merusak alam. Limbah tersebut terutama berasal dari proses pewarnaan batik yang masih menggunakan pewarna sintesis naptol, remasol, indigosol, dan sejenisnya. Bahan pewarna kimia pada batik tersebut tergolong tidak ramah lingkungan. Apabila limbah-limbah mengalir ke dalam tanah, bahan-bahan tersebut tentu merusak ekosistem tanah. Pasalnya, bakteri tanah tidak mampu mendegradasi bahan-bahan kimia. Penggunaan pewarna sintetis pun mulai mendapat ktitik tajam dalam beberapa dekade terakhir, para aktivis lingkungan mulai menentang penggunaan pewarna sintetis, dan konsumen mulai bersikap enggan terhadap produk dengan warna sintetis, serta lebih menyukai pewarna alami. Pada tahun 1960, para aktivis lingkungan di Amerika Serikat menentang penggunaan pewarna sintetis dan sikap ini menyebar luas. Aktivis lingkungan hidup mengkampanyekan penggunaan pewarna alami, hasilnya jumlah warna buatan yang diizinkan berkurang, dan kesadaran konsumen pada pewarna alami meningkat signifikan
(Rymbai et al., 2011). Pasar atau konsumen produk kerajinan saat ini juga semakin tertarik membeli produk yang dibuat dari bahan alami (Raharjo, 2011), yang dimanfaatkan secara optimal dengan menghasilkan sisa buangan seminimal mungkin (Eskak \& Salma, 2019). Masyarakat konsumen lokal maupun global mulai mengapresiasi penggunaan kembali pewarna alami untuk berbagai produk industri, termasuk batik.

Pewarna alami merupakan pewarna yang tidak mengandung racun (toxic), dapat diperbaharui (renewable), mudah terdegradasi alam, dan menghasilkan warna yang khas (Amalia \& Akhtamimi, 2016). Bahan pewarna alami dapat diperoleh dari pengolahan bahanbahan alam di daerah sekitar pengrajin batik, tidak bergantung impor seperti bahan pewarna sintetis. Produk ramah lingkungan sesuai untuk konsumen modern yang lebih memperhatikan kelestarian lingkungan (Purnama et al., 2017), dan sesuai isu green product pasar global (Purwanto, 2018). Zat warna alam bersifat non karsinogenik sehingga nyaman dan aman jika dipakai oleh manusia, efek intensitas warna terhadap kornea mata terasa lebih menyejukkan hingga dapat menyehatkan (Siregar, 2016). Keunggulan ramah lingkungan dan tidak menyebabkan hal buruk pada keseahatan manusia, maka sepatutnya produk batik kembali menggunakan zat pewarna alami. Perpaduan alam (tumbuhan) dan budaya (seni batik) dapat dibangkitkan lagi untuk industri kreatif masa kini sehingga dapat turut meningkatkan kesejahteraan masyarakat (Yoga \& Eskak, 2015), serta melestarikan lingkungan alam untuk kehidupan generasi mendatang.

Penggunaan zat pewarna alami walaupun pilihan yang dianjurkan, tetapi masih banyak kendala dalam ketersediaannya. Salah satu kendalanya adalah masih terbatasnya pasokan bahan pewarna karena umumnya masih mengambil bahan baku langsung dari kebun atau hutan. Oleh karena itu perlu dicari bahan pewarna alami dari sumber 
lain yang persediaannya melimpah dan kontinyuitas pasokannya lancar yaitu pemanfaatan limbah perkebunan. Kajian ini bermanfaat untuk mengetahui jenisjenis limbah perkebunan yang dapat dimanfaatkan untuk bahan pewarna alami untuk pewarnaan industri batik.

\section{PEMBAHASAN}

Potensi bahan baku zat pewarna alami dari sumber tanaman perkebunan di Indonesia sangat besar. Keunggulan sumber pewarna alami berbasis perkebunan adalah ketersediaan melimpah dan berkesinambungan, mudah didapatkan, murah, dan memberi dampak positif untuk masyarakat sekitar perkebunan. Perkebunan dalam hal ini adalah perkebunan besar baik milik negara ataupun swasta serta perkebunan rakyat. Adapun yang akan dibahas adalah pemanfaatan limbah perkebunan yaitu limbah kulit buah kakao, limbah sabut kelapa, limbah cangkang kelapa sawit, limbah kulit buah manggis, limbah kulit buah rambutan, limbah daun jambu biji, limbah daun mangga, dan limbah daun alpukat, yang dapat dimanfaatkan untuk bahan pewarna alami dalam industri batik.

\section{Limbah Kulit Buah Kakao}

Data dari International Cocoa Organization (ICCO) (2012) menyebutkan bahwa hasil kakao Indonesia (13\%) merupakan terbesar ketiga setelah Pantai Gading (39\%) dan Ghana (19\%). Perkebunan kakao tersebar di seluruh Indonesia, namun secara khusus kakao merupakan komoditas industri unggulan Provinsi Sulawesi Selatan tahun 20182038 sesuai Rencana Pembangunan Industri Provinsi (RPIP) adalah kakao, kopi, dan markisa (Zulkifli dan Akil, 2019).

Biji kakao dapat diolah menjadi bermacam-macam produk (Ramlah dan Sampebarra, 2018). Proses pengolahan kakao menyisakan limbah, antara lain berupa kulit buah. Limbah pengolahan kakao antara lain berupa kulit buah dan plasenta, yang dimanfaatkan sebagai pakan ternak maupun dibusukkan di sekitar kebun menjadi pupuk organik.
Potensi pemanfaatan kulit buah kakao masih cukup terbuka lebar mengingat sumber bahan baku berlimpah. Kulit buah kakao mempunyai potensi sebagai sumber pewarna alami karena kulit buah kakao mengandung senyawa flavonoid dan saponin (Pujilestari et al., 2016). Kulit buah kakao juga mengandung alkaloid theobromine dan tanin (Rachmawaty et al., 2017). Nilai ketahanan luntur warna pada kain batik katun dan sutera baik (nilai 4-5) dari rentang nilai 1-5 (Pujilestari et al., 2016). Warna yang dihasilkan masuk pada kelompok warna darksalmon yaitu arah warna merah dan kuning (Haerudin et al., 2020).

\section{Limbah Sabut Kelapa}

Kelapa (Cocos nucifera L.) merupakan tanaman populer bagi masyarakat yang hidup di daerah beriklim tropis. Buah yang dihasilkannya sebenarnya merupakan biji yang berukuran besar. Tumbuhan ini dimanfaatkan hampir semua bagiannya oleh manusia sehingga disebut sebagai tumbuhan serba guna (Eskak, 2016). Luas areal pohon kelapa di Indonesia yaitu kebun rakyat 3.443 .783 hektar, kebun negara 15.522 hektar, dan kebun swasta 64.543 hektar (Kasmudjo, 2013). Pemanfaatan buah kelapa untuk berbagai keperluan bahan makanan sehari-hari maupun untuk komoditas agroindustri menyisakan limbah, salah satunya adalah kulit terluar atau sabut. Sebenarnya limbah sabut kelapa telah diolah menjadi berbagai produk, namun karena ketersediaan sumber bahan sabut kelapa begitu besar, maka masih banyak yang belum termanfaatkan oleh industri maupun masyarakat. Jadi pemanfaatan limbah sabut untuk pewarnaan alami batik masih tersedia dengan melimpah dan murah.

Sabut kelapa merupakan bagian kulit buah kelapa yang dapat digunakan sebagai bahan pewarna alami, karena mengandung senyawa tanin (Dewi, 2014; Rohaeni, 2016). Senyawa tanin terkandung dalam partikel sabutnya. Senyawa ini merupakan senyawa polifenol yang memiliki struktur kompleks. 
Strukturnya yang juga merupakan golongan flavonoid merupakan senyawa turunan dari benzena. Senyawa tanin group flavonoid ini bila direndam dalam air akan mengeluarkan warna coklat kemerahan, agar zat warna dapat terserap dengan baik pada kain maka diperlukan bahan pembangkit seperti cuka, gula batu dan air kelapa. Fungsi bahan pembangkit selain untuk memperkuat daya serap zat warna ke dalam kain, adalah untuk mengetahui arah warna yang dihasilkan dari zat warna alam sabut kelapa (Dewi, 2014). Limbah sabut kelapa menghasilkan arah warna abu-abu, coklat muda, coklat tua, dan hitam tergantung fiksator yang digunakan (Fitriyah \& Ciptandi, 2018; Nurmaini, 2019).

\section{Limbah Cangkang Kelapa Sawit}

Kelapa sawit (Elaeis guinensis $J A C Q$ ) merupakan komoditas perkebunan unggulan Indonesia. Tanaman yang produk utamanya terdiri dari minyak sawit (CPO) dan minyak inti sawit (KPO) ini memiliki nilai ekonomis tinggi dan menjadi salah satu penyumbang devisa negara yang besar. Minyak kelapa sawit diperoleh dari pengolahan buah kelapa sawit. Pengolahan minyak sawit dan produk turunannya menyisakan limbah, salah satunya berupa cangkang kelapa sawit. Limbah perkebunan kelapa sawit merupakan sisa hasil proses pengolahan yang tidak termasuk dalam produk utama yang dianggap berpotensi menjadi beban pencemaran lingkungan jika tidak dikelola dengan baik (Elykurniati, 2011), karena cangkang kelapa sawit keras dan cukup lama terdegradasi secara alami di tanah. Apabila limbah ini diproses secara tepat akan memberikan manfaat dan nilai tambah yang cukup besar bagi masyarakat dan industri.

Limbah cangkang kelapa sawit jumlahnya cukup besar dan mempunyai potensi untuk dimanfaatkan sebagai pewarna untuk batik karena adanya kandungan pigmen (Pujilestari et al,. 2016). Pigmen warna tumbuhan tidak permanen sehingga warna cepat memudar apabila terkena deterjen atau cahaya matahari. Agar zat warna alam mempunyai ketahanan luntur yang baik maka diperlukan proses fiksasi (Shofwan, 2015). Bahan fiksator berguna untuk mengunci atau mengikat warna yang telah terserap kain. Arah warna alam limbah cangkang kelapa sawit coklat tipis dan keabu-abuan (Pujilestari et al., 2016), seperti arah warna alam dari kulit soga jambal (Pelthophorum ferruginum) (Susanto, 2018). Warna dari limbah cangkang kelapa sawit tidak sepekat warna dari limbah kulit buah kakao, namun ketahanan luntur warna terhadap pencucian lebih baik. Warna paling baik diperoleh dari warna cangkang kelapa sawit pada kain sutera menggunakan fiksasi tawas (Pujilestari et al., 2016).

\section{Limbah Kulit Manggis}

Buah manggis

(Garcinia mangostana $L$ ) banyak disukai banyak orang, karena rasanya yang manis dan segar. Pohon manggis banyak ditanam masyarakat sebagai penghasil buah serta untuk penghijauan karena pohonnya cukup besar serta rimbun daunnya yang memberikan kesejukan lingkungan sekitarnya. Perkebunan buah manggis terbesar ada di Jawa barat yang meliputi daerah Subang, Purwakarta, Bogor, Sukabumi, serta Tasikmalaya yang buahnya telah diekspor ke beberapa negara di Asia dan Eropa (Fikri, 2018). Perkebunan manggis juga terdapat di Jawa Tengah, Yogyakarta, Jawa Timur, dan beberapa daerah lainnya. Konsumsi buah segar dan olahan awetan menyisakan limbah berupa kulit buah.

Kulit buah manggis mengandung banyak manfaat mulai dari bahan obat herbal sampai bahan untuk pembuatan pewarna alami, termasuk untuk pewarnaan kain batik (Suheryanto, 2017). Warna yang dihasilkan adalah coklat muda dan coklat kemerahan (Manurung, 2012); serta warna kemerahan (Wulaningrum et al., 2013), pada pewarnaan kain katun. Pewarnaan alami pada kain batik bahan katun dengan ekstrak kulit buah manggis yang difiksasi dengan kapur, tawas, atau tunjung, dapat memberikan ketahanan luntur yang baik 
(Pujilestari, 2014).

\section{Limbah Kulit Rambutan}

Rambutan

lappaceum) merupakan tanaman

penghasil buah tropis yang masih satu keluarga dengan kelengkeng, leci dan matoa. Tanaman ini banyak dibudidayakan di Indonesia, Thailand, dan Malaysia (Risnandar, 2018). Buah rambutan dikonsumsi sebagai buah segar juga dapat dikalengkan serta variasi olahan yang lainnya. Buahnya dapat diolah menjadi salad buah, jus dan jeli. Biji rambutan digoreng dikonsumsi sebagai camilan. Biji rambutan diambil sari minyaknya dapat digunakan sebagai minyak goreng (Junita, 2018). Pengolahan tersebut menyisakan limbah berupa kulit buah. Kulit buah ini memiliki kandungan flavonoida yang merupakan pigmen yang dapat dimanfaatkan sebagai pewarna alami tekstil (Prasetio, 2014). Hasil uji ketahanan luntur warna dari limbah kulit rambutan menunjukkan bahwa penggunaan zat fiksasi tawas memberikan nilai ketahanan luntur yang lebih baik dibandingkan dengan zat fiksasi kapur dan tunjung sedangkan pada konsentrasi zat fiksasi yang berbeda menunjukkan bahwa pada penggunaan konsentrasi bahan fiksasi yang lebih tinggi ( $25 \%$ dan $45 \%$ ), nilai greyscale dan stainingscale akan semakin baik (Amalia \& Akhtamimi, 2016).

\section{Limbah Daun Jambu Batu}

Jambu batu (Psidium guajava) atau sering juga disebut jambu biji, jambu siki dan jambu klutuk adalah tanaman buah tropis yang banyak mengandung vitamin C. Tanaman ini berasal dari Brasil yang menyebar ke Indonesia melalui Thailand (Hadiati \& Apriyanti, 2015). Jambu batu merupakan buah yang populer dan banyak ditanam di pekarangan oleh masyarakat, namun juga ditanam dalam perkebunan yang cukup besar, misalnya di Kendal, Jawa Tengah terdapat perkebunan jambu biji terbesar di Indonesia seluas 2.000 hektar, dengan panen 60-70 ton dalam satu hektarnya (Jatengpos, 2018). Perkebunan jambu biji juga ada di beberapa daerah baik yang dikelola mandiri, kelompok tani, maupun sebagai agrowisata.

Selain untuk bahan obat herbal, daun jambu ini secara tradisional juga telah dimanfaatkan untuk pewarnaan batik (Susanto, 2018). Limbah daun jambu batu diperoleh dari proses pemangkasan cabang berkala untuk memicu semai tunas dan bunga agar menghasilkan panen buah yang maksimal (Sitanggang, 2020). Limbah daunnya dapat dimanfaatkan sebagai bahan pewarna batik. Arah warna yang dihasilkan adalah coklat kehijauan sampai coklat kehitaman sesuai dengan fiksator yang digunakan, bila fiksatornya tawas atau kapur hasilnya cenderung muda, bila fiksatornya tunjung warna cenderung lebih tua (Siregar, 2016).

\section{Limbah Daun Mangga}

Pohon mangga (Mangifera indica linn) merupakan tanaman yang populer dan banyak ditanam orang, karena disukai rasa buahnya serta untuk penghijauan lingkungan. Perkebunan mangga banyak dikelola dalam skala kecil, sedang maupun besar (Winarta, 2017). Pada tahun 2018 perkebunan mangga di Indonesia seluas 202.838 hektar, dan lahan terluas berada di Provinsi Jawa Timur yang mencapai 83.353 hektare. Perkebunan mangga hampir merata di seluruh wilayah tanah air, karena buahnya mudah laku baik untuk dijual lokal maupun ekspor (Prayogo, 2019).

Daun mangga dapat dimanfaatkan untuk bahan pewarna alami batik. Sediaan daun mangga melimpah diperoleh dari pemangkasan berkala untuk memicu pohon berbuah secara maksimal (Herdiani, 2014). Ektraksi klorofil dari daun mangga dapat menghasilkan pigmen warna alami untuk batik (Pujilestari, 2014; Putri et al. 2019). Arah warna yang dihasilkan dengan mordanting awal dan iring menggunakan tawas adalah kuning, jeruk nipis adalah kuning muda, baking soda adalah cokelat dan ferro sulfat adalah abu-abu. Mordanting yang menghasilkan warna 
paling baik secara visual pada kain sutera adalah mordanting iring (Subjana, 2014). Ketahanan luntur warnanya yang difiksasi dengan tawas bernilai baik (Pujilestari, 2014).

\section{Limbah Daun Alpukat}

Tanaman alpukat (Persea americana) berasal dari Amerika Tengah dan Meksiko. Dikembangkan di Indonesia pertama kali oleh Belanda pada tahun 1800-an. Dewasa ini buah alpukat semakin disukai banyak orang dan banyak ditanam dalam pekarangan maupun perkebunnan. Prospek bisnis buah yang bagus menjadikan alpukat ditanam dalam perkebunan serta agrowisata, antara lain di Yogyakarta, Jawa Tengah (Sudjatmiko, 2020), Jawa Timur (Arifin, 2019), dan beberapa daerah lainnya.

Tanaman alpukat perlu perawatan antara lain adalah pemangkasan ranting dan cabang. Pemangkasan dilakukan pada cabang-cabang yang tumbuh terlalu rapat atau ranting-ranting yang mati (Wicahyo, 2019). Pemangkasan ini menghasilkan limbah berupa ranting dan daun. Daun alpukat mengandung senyawa flavonoid, tanin dan kuinon. Tanin merupakan zat pewarna yang menimbulkan warna coklat atau kecoklatan (Lestari, 2014). Dengan demikian, daun alpukat dapat dimanfaatkan menjadi zat warna alami pada batik. Kepekatan warna dari pewarna alam daun alpukat dan ketahanan lunturnya mendapat derajat baik dan sangat baik (4-5) dari rentang nilai 1-5 (Saputry, 2018).

\section{SIMPULAN}

Sumber pewarna alami dari tumbuhan yang potensial adalah pemanfaatan limbah dari pengolahan hasil perkebunan. Limbah dari perkebunan yang dapat digunakan untuk batik pewarna alami adalah limbah kulit kakao, limbah sabut kelapa, limbah cangkang kelapa sawit, limbah kulit rambutan, limbah kulit manggis, limbah daun jambu batu, limbah daun mangga, dan limbah daun alpukat. Bahan-bahan tersebut mengandung pigmen yang menghasilkan arah warna bernuansa kuning, kemerahan, kecoklatan, abu-abu dan kehitaman. Ketahanan luntur warna juga baik, sehingga layak dimanfaatkan sebagai substitusi bahan pewarna alami untuk industri batik.

\section{Saran}

Penelitian lanjutan senantiasa perlu dilakukan untuk menyempurnakan hasil yang telah didapatkan. Perlu dukungan berbagai pihak untuk lebih menggalakkan lagi pemanfaatan pewarna alami pada industri batik, agar pencemaran akibat penggunaan pewarna sintetis dapat dikurangi. Penelitian pemanfaatan limbah hasil perkebunan komoditas yang lain juga perlu dilakukan untuk mendapatka lebih banyak varian bahan baku pewarna alami dan variasi warna yang lebih beragam.

\section{DAFTAR PUSTAKA}

1. Amalia, R. \& Akhtamimi, I. (2016). Studi Pengaruh Jenis dan Konsentrasi Zat Fiksasi Terhadap Kualitas Warna Kain Batik dengan Pewarna Alam Limbah Kulit Buah Rambutan (Nephelium lappaceum). Dinamika Kerajinan dan Batik, 33(2), 8592.

2. Andansari, D., \& Nadir, M. (2017). Eksplorasi Pewarnaan Beberapa Jenis Kain Menggunakan Pewarna Alami Jolawe dan Secang dengan Fiksasi Tawas, Baking Soda dan Jeruk Nipis. Jurnal Kreatif, 4(2), 32-40.

3. Arifin, Z. (2019). Berkebun Pagi Hari ke Sentra Alpukat di Lereng Gunung Arjuno. Retrieved from https://www.liputan6.com/regional/read/3 949677/berkebun-pagi-hari-ke-sentraalpukat-di-lereng-gunung-arjuno

4. Atika, V., Farida, \& Pujilestari , T. (2016). Kualitas Pewarnaan Ekstrak Gambir Pada Batik Sutera. Dinamika Kerajinan dan Batik, 33(1), 25-32.

5. Dewi, R. P. (2014). Studi Pencelupan Kain Katun Menggunakan Ekstraksi Sabut Kelapa Dengan Fiksator Cuka, Gula Batu, dan Air Kelapa. Universitas Negeri Malang.

6. Elykurniati. (2011). Pemanfaatan Limbah Padat cangkang Kelapa Sawit dalam Pembuatan Pupuk Cair Kalium Sulfat. UPN Jatim Surabaya. 
7. Eskak, E. \& Salma, I. R. (2019). Jepara Wooden Carving in the Digital Era. In S. G. Kaburuan, E. R., Nainggolan O. T. P., Hapsari, P. D. \& Gunanto (Ed.), The 1st International conference on intermedia arts and creative technology (CREATIVEARTS 2019) (pp. 31-39). Yogyakarta: SCITEPRESS - Science and Technology Publications, Lda: Portugal.

8. Eskak, E. (2014). Pemanfaatan Limbah Ranting Kayu Manis (Cinnamomun Burmanii) untuk Penciptaan Seni Kerajinan dengan Teknik Laminasi. Dinamika Kerajinan dan Batik, 31(2), 6574.

9. Eskak, E. (2016). Identifikasi Pola Laminasi Tempurung Kelapa. Dinamika Kerajinan dan Batik, 32(2), 107-116.

10. Fikri, A. (2018, November). Mangga Gedong Gincu Jawa Barat Ditargetkan Tembus Jepang. Tempo. Retrieved from https://bisnis.tempo.co/read/1144484/ma ngga-gedong-gincu-jawa-baratditargetkan-tembus-jepang/full\&view=ok

11. Fitriyah, H. \& Ciptandi, F. (2018). Pengolahan Limbah Sabut Kelapa Tua Sebagai Pewarna Alam Pada Produk Fesyen. In e-Proceeding of Art \& Design (pp. 2534-2553). Bandung: Telkomuniversity.

12. Gardjito, M. (Ed.). (2015). Batik Indonesia Mahakarya Penuh Pesona. Jakarta: Kaki langit Kencana.

13. Hadiati, S. \& Apriyanti, L. H. (2015). Bertanam Jambu Biji di Pekarangan. Jakarta: Penebar Swadaya.

14. Haerudin, A., Atika, V., Isnaini, Masiswo, Mandegani, G. B., Satria, Y., Lestari, D. W., Arta, T. K., Fitriani, A., \& Hardjanto, P. (2020). Pengaruh Variasi Waktu, Ph, dan Suhu Ekstraksi Terhadap Kualitas Pewarnaan Ekstrak Kulit Buah Kakao Pada Batik Katun dan Sutera. Dinamika Kerajinan dan Batik, 37(1), 25-40.

15. Haerudin, A., Pujilestari, T., \& Atika, V. (2017). Pengaruh Jenis Pelarut Terhadap Hasil Ekstraksi Rumput Laut Gracilaria Sp. Sebagai Zat Warna Alam pada Kain Batik Katun dan Sutera. Dinamika Kerajinan dan Batik, 34(2), 83-92.

16. Handayani, P. A., \& Maulana, I. (2013). Pewarna Alami Batik dari Kulit Soga Tingi (Ceriops tagal) dengan Metode Ekstraksi. Jurnal Bahan Alam Terbarukan, 2(2), 1-6.

17. Herdiani, E. (2014). Pemangkasan Tanaman Mangga. Retrieved July 12,
2020, from http://www.bbpplembang.info/index.php/arsip/artikel/artik el-pertanian/788-pemangkasan-tanamanmangga

18. ICCO. (2012). International Cocoa Organization Quarterly Bulletin of Cocoa Statistics, Vol. XXXVIII, No. 4, Cocoa year 2011/2012. Retrieved July 9, 2019, from https://www.icco.org/about-us/icconews/210-november-2012-quarterlybulletin-of-cocoa-statistics.html

19. Jatengpos. (2018). Kendal Sentra Jambu Biji Merah Terbesar di Indonesia. Retrieved from http://jatengpos.co.id/kendal-sentrajambu-biji-merah-terbesar-di-indonesia/

20. Junita, N. (2018). Manfaat Rambutan untuk Kesehatan dan Faktanya. Retrieved from https://lifestyle.bisnis.com/read/20181204 /106/865976/-manfaat-rambutan-untukkesehatan-dan-faktanya

21. Kant, R. (2012). Textile Dyeing Industry an Environmental Hazard. Natural Science, 4(1), 5.

22. Kartina, B., Ashar, T., \& Hasan, W. (2013). Karakteristik Pedagang, Sanitasi Pengolahan dan Analisa Kandungan Rhodamin B pada Bumbu Cabai Giling di Pasar Tradisional Kecamatan Medan Baru Tahun 2012. Lingkungan Dan Kesehatan Kerja, 1(2), 1-7.

23. Kasmudjo. (2013). Rotan, Bambu, Kelapa, Kelapa Sawit, Nipah, dan Sagu: Potensi dan Daya Guna. Yogyakarta: Cakrawala Media.

24. Lestari, D. W., Isnaini, Salma, I. R., \& Satria, Y. (2018). Bentonit sebagai Zat Mordan dalam Pewarnaan Alami pada Batik Menggunakan Kayu Secang (Caesalpinia Sappan Linn.). Dinamika Kerajinan dan Batik, 35(2), 95-102.

25. Lestari, P. (2014). Ekstraksi Tanin dari Daun Alpukat (Persea Americana Mill.) Sebagai Pewarna Alami (Kajian Proporsi Pelarut dan Waktu Ekstraksi). Universitas Brawijaya.

26. Manurung, M. (2012). Aplikasi Kulit Buah Manggis (Garcinia Mangostana L.) Sebagai Pewarna Alami pada Kain Katun secara Pre-Mordanting. Jurnal Kimia, 6(2), 183-190.

27. Muniarti, T., Inayati \& Budiastuti, S. (2015). Pengelolaan Limbah Cair Industri Batik dengan Metode Elektrolisis sebagai Upaya Penurunan Tingkat Konsentrasi Logam Berat di Sungai Jenes, Laweyan, Surakarta. Jurnal EKOSAINS, 7(1), 77- 
83.

28. Nurmaini, A. (2019). Perbedaan Hasil Pencelupan Menggunakan Zat Warna Alam Eksrtak Sabut Kelapa Muda dan Ekstrak Sabut Kelapa Tua Pada Bahan Katun Dengan Mordan Air Kelapa. Jurnal Kapita Selekta Geografi, 2(9), 149-164.

29. Paryanto, P., Hermiyanto, H., \& Sanjaya, S. D. S. (2013). Pembuatan Zat Warna Alami dari Biji Kesumba dalam Bentuk Konsentrat Tinggi Untuk Pewarna Makanan. Metana, 9(2), 41-45.

30. Prasetio, D. (2014). Studi Pemanfaatan Kulit Buah Rambutan (Naphelium Lappaceum, Linn) Sebagai Pewarna Alami Tekstil. UIN Sunan Kalijaga.

31. Prayogo, C. (2019). Menyimak Produksi Mangga di Indonesia. Retrieved from https://www.wartaekonomi.co.id/read250 992/menyimak-produksi-mangga-diindonesia

32. Pujilestari, T., Farida, Pristiwati, E., Haerudin, A., \& Atika , V. (2016). Pemanfaatan Zat Warna Alam dari Limbah Perkebunan Kelapa Sawit dan Kakao Sebagai Bahan Pewarna Kain Batik. Dinamika Kerajinan dan Batik, 33(1), 1-8.

33. Pujilestari, T. (2014). Pengaruh ekstraksi zat warna alam dan fiksasi terhadap ketahanan luntur warna pada kain batik katun. Dinamika Kerajinan dan Batik, 31(1), 31-40.

34. Purnama, H., Hidayati, N., S. Safitri, D., \& Rahmawati, S. (2017). Effect of Initial Treatment in the Preparation of Natural Indigo Dye from Indigofera Tinctoria. In AIP Conference Proceedings 1855, 020022. New York: AIP Publishing's.

35. Purwanto. (2018). Pemanfaatan Bahan Pewarna Alam Sebagai Alternatif dalam Pembuatan Batik Tulis Yang Ramah Lingkungan. In Seminar Nasional Aplikasi Sains \& Teknologi (SNAST). Yogyakarta.

36. Putri, N. K. T. C., Ratnawati, I. G. A. A., D., \& Suharta, W. G. (2019). Analisis Pigmen Alami Daun Mangga (Mangifera Indicalinn) Sebagai Pewarna Batik Dengan UV-VIS. Kappa Journal, Pendidikan Fisika, FMIPA, Universitas Hamzanwadi., 3(2), 134-141.

37. Rachmawaty, Mu'nisa, A., \& H. (2017). Analisis Fitokimia Ekstrak Kulit Buah Kakao (Theobroma cacao L.) Sebagai Kandidat Antimikroba. In Prosiding Seminar Nasional (pp. 667-670). Makassar: Universitas Negeri Makasar.
38. Raharjo, T. (2011). Seni Kriya dan Seni Kerajinan. Yogyakarta: Program Pascasarjana ISI Yogyakarta.

39. Rame, Purwanto, A., \& Budiarto, A. (2017). Pengolahan Air Limbah Tekstil Berbasis Ozonisasi Katalitik dengan Katalis Besi (III) oksida (Fe2O3) dan Aluminium oksida (Al2O3) Menggunakan Difuser Mikro. Jurnal Riset Teknologi Pencegahan Pencemaran Industri, 8(2), 67-75.

40. Risnandar, C. (2018). Buah Rambutan. Retrieved July 12, 2020, from https://jurnalbumi.com/knol/buahrambutan/

41. Rohaeni, N. S. (2016). Kajian Konsentrasi Pelarut Terhadap Ekstrak Pigmen dari Sabut Kelapa (Cocos Nucifera L) Sebagai Pewarna Alami. Universitas Pasundan Bandung.

42. Ruslan \& Wiraningtyas, A. (2019). Ekstraksi Zat Warna Dari Rumput Laut Sargassum Sp. Jurnal Redoks: Jurnal Pendidikan Kimia Dan IImu Kimia, 2(1), $1-10$. https://doi.org/https://doi.org/10.33627/re. v2i01.72

43. Rymbai, H., Sharma, R.R., and Srivasta, M. (2011). Bio-colorants and Its Implications in Health and Food IndustryA Review. International Journal of Pharmacological Research, 3, 22282244.

44. Salma, I. \& Eskak, E. (2019). The Existence of Batik in the Digital Era. In S. G. Kaburuan, E. R., Nainggolan O. T. P., Hapsari, P. D. \& Gunanto (Ed.), The 1st International conference on intermedia arts and creative technology (CREATIVEARTS 2019) (pp. 40-49). Yogyakarta: SCITEPRESS - Science and Technology Publications, Lda: Portugal.

45. Saputry, A. R. D. A. (2018). Kualitas Pewarna Alami Kain Batik dari Organ Daun Beberapa Tanaman dengan Variasi Lama Perendaman. Universitas Muhammadiyah Surakarta.

46. Satria, Y., \& Suheryanto, D. (2016). Pengaruh Temperatur Ekstraksi Zat Warna Alam Daun Jati Terhadap Kualitas dan Arah Warna Pada Batik. Dinamika Kerajinan dan Batik, 33(2), 101-110.

47. Shofwan, A. (2015). Studi Tentang Pewarnaan Alami Bunga Belimbing Sayur Pada Kain Serat Nanas Menggunakan Fiksator Tunjung, Tawas dan Kapur Tohor. Universitas Negeri 
Malang.

48. Sima, A. (2019). Pewarnaan kain menggunakan ekstrak zat warna alami dari kelopak bunga rosella (Hibiscus sabdariffa L.). Universitas Parahiyangan.

49. Siregar, A. H. (2016). Pembuatan Zat Warna Alam Dari Tumbuhan Berasal dari Daun. Bina Teknika, 12(1), 103-110.

50. Sitanggang, S. (2020). Tips agar Jambu Biji Rajin Berbuah. Retrieved July 12, 2020,

from

http://cybex.pertanian.go.id/mobile/artikel /90466/Tips-agar-Jambu-Biji-Rajin-

Berbuah/

51. Sitti Ramlah, S. \& Barra, A. L. S. (2018). Karakteristik dan Citarasa Cokelat Putih dari Lemak Kakao Non Deodorisasi dan Deodorisasi Daerah. Jurnal Industri Hasil Perkebunan, 13(2), 117-128.

52. Suarsa, I.W., Suarya, P., \& Kurniawati, I. (2011). Optimasi Jenis Pelarut dalam Ekstraksi Zat Warna Alam dari Batang Pisang Kepok (Musa paradiasiaca L. cv kepok ) dan Batang Pisang Susu (Musa paradiasiaca L. cV susu). Journal of Chemistry, 5(1): 72-80., 5(1), 72-80.

53. Subjana, V. G. (2014). Eksperimen Warna Alam Mangga Arumanis, Mangga Gedong Gincu dan Mangga Simanalagi Sebagai Pewarna Kain Sutera. Universitas Pendidikan Indonesia.

54. Sudjatmiko, T. (2020). Generasi Muda Temanggung Tekuni Budidaya Alpukat, Ini Alasannya. Retrieved from https://www.krjogja.com/ekonomi/inspiras i/generasi-muda-ini-tekuni-budidayaalpukat-ini-alasannya/2/

55. Suheryanto, D. (2017). Natural Dyes Ensiklopedia Zat Warna Alami dari Tumbuhan untuk Industri Batik. Yogyakarta: Penerbit Andi.

56. Susanto, S. K. S. (2018). Seni Kerajinan Batik Indonesia. (Tim Ahli BBKB, Ed.). Yogyakarta: ANDI.

57. Visalakshi, M., \& Jawaharlal, M. (2013). Healthy Hues-Status and Implication in Industries - Brief Review. Journal of Agriculture and Allied Sciences, 3(2), 4251.

58. Wicahyo, H. (2019). Panduan Menanam Alpukat di Pekarangan Rumah. Retrieved July 12, 2020, from https://daunku.com/tutorial-menanamalpukat/

59. Widjajanti, E., Regina T.P., \& Utomo, M. P. (2011). Pola Adsorpsi Zeolit Terhadap Pewarna Azo Metil Merah dan Metil Jingga. In Prosiding Seminar Nasional
Penelitian: Pendidikan dan Penerapan MIPA (pp. K115-K122). Yogyakarta: Fakultas MIPA, Universitas Negeri Yogyakarta.

60. Winarta, K. (2017, November). Produksi Mangga di Indonesia Terbesar Nomor 4 di Dunia. TrubusNews. Retrieved from https://news.trubus.id/baca/3608/produks i-mangga-di-indonesia-terbesar-nomor-4di-dunia

61. Wulaningrum, R. A, Sunarto, W., \& Alauhdin, M. (2013). Pengaruh Asam Organik dalam Ekstraksi Zat Warna Kulit Buah Manggis (Garcinia mangostana). Indonesian Journal of Chemical Science, 2(2), 119-124.

62. Yoga, W. B. S., \& Eskak, E. (2015). Ukiran Bali Dalam Kreasi Gitar Elektrik. Dinamika Kerajinan dan Batik, 32(2), 117-126.

63. Yuningrat, N. Y., Ayuni, N. S. P., Martiningsih, N. W., Gunamantha, I. M., \& Widana, G. A. B. (2018). Teknologi Tepat Guna Pengolahan Limbah Tekstil Bagi Industri Tenun Bintang Timur. Jurnal Widya Laksana, 7(1), 92-99.

64. Zulkifli \& Akil, A. (2019). Analisis Kebijakan Rencana Pembangunan Industri Provinsi Sulawesi Selatan (Komoditas Kakao, Kopi Dan Markisa). Jurnal Industri Hasil Perkebunan, 14(1), 78-97. 